\title{
Panorama da Gestão Financeira dos Restaurantes do Município de Petrolina-PE
}

\author{
Panorama of the Financial Management of the Restaurants of the Municipality of \\ Petrolina-PE
}

\author{
Dherverson Dias Evangelista*1 $^{*}$, Erika Jamir de Oliveira² \\ ${ }^{1}$ Centro Universitário Maurício de Nassau - UNINASSAU, Pernambuco, Brasil. \\ ${ }^{2}$ Instituto Federal do Piauí - IFPI, Piauí, Brasil.
}

\section{N F ARTIGO}

\section{Palavras-chave:}

Ferramentas Financeiras, Restaurantes,

Gestão,

Custos.

\section{ARTICLE INFO}

\section{Keywords:}

Financial Tools,

Restaurants,

Management,

Cost Management.

\begin{abstract}
RESUMO
Munir-se de ferramentas para a gestão financeira pode ser um meio para manter-se competitivo frente a seus concorrentes, garantir a sobrevivência, desenvolvimento e retorno financeiro positivo do empreendimento. $\mathrm{O}$ objetivo desta pesquisa foi descrever o panorama da gestão financeira dos restaurantes do município de Petrolina. A pesquisa caracteriza-se pela abordagem de métodos mistos, utilizou-se como técnica de levantamento, a amostra foi de 48 gestores de restaurantes, a coleta foi realizada por meio de entrevista, instrumentalizada por um questionário. Foi constatado que mais de $50 \%$ usam pelo menos uma ferramenta financeira, $83 \%$ deles têm problemas relacionados à gestão financeira, 64\% utiliza ou já utilizou dinheiro da empresa para fins externos, aproximadamente $41 \%$ deles não conseguem manter seu capital de giro constantemente positivo. Essa pesquisa fornece informações que trazem alertas para a necessidade de estabelecer parceria com órgãos de fomento, visando a introdução de cursos direcionados a aplicação de ferramentas financeiras e gestão empresarial.
\end{abstract}

\footnotetext{
* Correspondência para autor:

dherverson@gmail.br (Evangelista, D. D.), erika.jamir@,ifpi.edu.br (Oliveira, E. J.).
} 


\section{Introdução}

As ferramentas financeiras são essenciais para que a empresa tenha fluidez e sinergia entre os seus setores, pois são responsáveis por otimizar tarefas e concentrar grande quantidade de informações que, porventura, trarão benefício para empresa possibilitando um planejamento adequado e maiores contribuições para o alcance dos objetivos organizacionais. Segundo Schneider (2011), a gestão financeira é responsável por estimar e definir, através da aplicação de instrumentos financeiros, os benefícios e prejuízos que determinada pessoa, seja física ou jurídica terá mediante a sua pecúnia.

De acordo com o Serviço de Apoio às Micro e Pequenas Empresas (2013), existem diversas barreiras por parte dos empreendedores que podem ser rigidamente familiares ou apegados a velhos paradigmas e não considerar ser necessário o acompanhamento e planejamento de suas empresas. Por isso, é importante descortinar que as ferramentas vêm projetar, controlar e facilitar a vida do gestor, evitando-se eventuais vazões de caixa que venham por impactar negativamente a empresa.

Estudos realizados por Junior (2017), Borges et al. (2015), Ribeiro e Estender (2017) e Cunha et al. (2017) referentes a técnicas e instrumentos financeiros, expõem a aplicação e importância do custeio do preço de venda, auditória interna, fluxo de caixa, balanço patrimonial e conciliações bancárias de forma supressiva, já a pesquisa a presente pesquisa, tem o diferencial de introduzi-los de maneira descomplicada e relevar que não importa o tipo de empreendimento, as técnicas financeiras podem estar presentes mesmo que de forma básica e até mesmo no cotidiano pessoal, logo, é possível de serem encontradas nos restaurantes convertendose alimentos em números.

Previamente, relacionado ao objeto da pesquisa, não foi encontrado nenhuma investigação sobre as técnicas e instrumentos para a gestão financeira aplicadas em restaurantes na cidade de Petrolina-PE. Posto isso e considerando a importância da realização de diagnósticos para que políticas públicas e agências de fomento possam direcionar sua tomada de decisão e seus esforços para consecução do fomento a atividade empreendedora da região, levantou-se a seguinte questão: quais ferramentas financeiras são utilizadas pelos restaurantes da cidade de Petrolina-PE?

Destarte, é certo que todo investidor ou dono de capital quer aumentar seu lucro, reduzir seus gastos e aumentar sua rentabilidade, para manter o controle e prever ações do ambiente interno e externo da organização, partindo deste pressuposto, o objetivo dessa investigação foi identificar as ferramentas financeiras utilizadas no auxílio à gestão financeira por Gerentes de restaurantes da Cidade de Petrolina.

\section{Ferramentas Financeiras de Gestão}

As ferramentas financeiras possibilitam ao gestor financeiro análise, controle e planejamento dos dados com a finalidade de gerar e organizar relatórios contendo informações de períodos passados, presentes e projeções futuras. Conforme o Sebrae (2017) "A gestão financeira compreende um conjunto de ações e procedimentos administrativos que visam maximizar os resultados econômicos e financeiros".

As ferramentas financeiras são bastante flexíveis e se interacionam mediante a complementos e aprofundamento das informações nelas contidas. A seguir, no Quadro 01, são apontadas algumas ferramentas e conceitos dados a ela por autores especialistas no assunto. 
Quadro 01: Ferramentas Financeiras Indispensáveis.

\begin{tabular}{|c|c|}
\hline Ferramenta & Conceito \\
\hline Controle de custos & $\begin{array}{l}\text { Ligada diretamente a contabilidade de custos, segundo Leone (2014) o } \\
\text { controle de custos funciona como uma rede central de informações, onde } \\
\text { recebe diversos dados oriundos da empresa, acumula-os e analisa-os de } \\
\text { forma estruturada, por fim interpreta-os e, por conseguinte, gerando } \\
\text { informações especificas referentes a diversos níveis gerenciais, através de } \\
\text { pré-relatórios para auxiliar os gestores. }\end{array}$ \\
\hline Auditória Interna & $\begin{array}{l}\text { Conforme Lins (2014) auditoria, de forma geral e simplificada, seja qual } \\
\text { for o tipo, significa conferencia, verificação, analise e avaliação, ou seja, é } \\
\text { a comunicação de resultados dentro de um determinado período, sendo a } \\
\text { interna do qual a ferramenta se propõe, sendo realizada pelo próprio } \\
\text { funcionário do qual a auditoria é executada, envolvendo diversos pontos a } \\
\text { serem auditados ligados ao objetivo. }\end{array}$ \\
\hline Fluxo de Caixa & $\begin{array}{l}\text { Segundo Braga (2015) o Fluxo de caixa são projeções de pagamentos e } \\
\text { recebimentos, ao decorrer da vida útil do projeto, sendo o ponto de partida } \\
\text { do orçamento, ou seja, o valor do dinheiro no tempo, através das } \\
\text { informações disponibilizadas por ele é possível calcular a Rentabilidade, } \\
\text { Lucratividade, Ponto de Equilíbrio, Prazos de Retorno de investimento, } \\
\text { dentre outras informações referentes ao empreendimento. }\end{array}$ \\
\hline Balanço Patrimonial & $\begin{array}{l}\text { De acordo com Braga (2015) o Balanço Patrimonial reflete a situação da } \\
\text { empresa em dado momento, pois no dia conseguinte as contas contidas } \\
\text { nesse balanço terão seus saldos modificados, apesar de possuir caráter } \\
\text { estático, o balanço patrimonial é a principal ferramenta contábil devido a } \\
\text { sua abrangência. }\end{array}$ \\
\hline Conciliações Bancárias & $\begin{array}{l}\text { São conferencias em determinada conta bancária da empresa com uso de } \\
\text { extratos bancários, onde realiza-se a conferência a fim de apurar o saldo } \\
\text { empresarial, afim de encontrar divergências no determinado período. }\end{array}$ \\
\hline
\end{tabular}

Fonte: LEONE (2014); LINS (2014); BRAGA (2015).

Junior (2017) demonstra de forma progressiva a aplicação do custeio no preço de venda dos produtos, expondo a importância da ferramenta de custos na formação do preço de venda de produtos e serviços, o uso de custeio por absorção, custos diretos, método $\mathrm{ABC}$, salientando a importância de apurar e conhecer seus custos, a fim de analisa-los e utilizá-los como poderosas fontes de conhecimento para planejamentos estratégicos futuros.

Nogueira (2016) aplicou a contabilidade de custos em um hospital com a finalidade de mapear e validar os subprocessos do manejo de resíduos de serviços de saúde no centro cirúrgico e calcular o custo dos materiais, demonstrando que a ferramenta é bastante flexível e pode se adaptar a diversos tipos de produtos e serviços, inclusive nos restaurantes com a finalidade de evitar desperdício, reduzir os custos, que por consequência aumentarão os lucros e, por fim, a reserva de capital reservada a despesas não programadas com a finalidade de não impactar o final do período.

Referente a auditoria interna, é fato que a mesma tem várias faces e pode ser aplicada de várias maneiras, apresentando também uma flexibilidade voltada para os riscos, Borges et al. (2015) procura expor que os auditores devem saber lidar com eles dentro de uma organização de saúde, agindo assim em interdependência, afim de mitigar e exaurir possíveis riscos que são estudados e aplicados do planejamento estratégico da empresa através de ferramentas e soluções eficazes.

Já na pesquisa de Ribeiro e Estender (2017), o fluxo de caixa é exposto na prática na organização estudada, com isso, possibilitou-se encontrar a solução dos problemas organizacionais relacionados a entradas e saídas, assim como especificação de todas as receitas e despesas com intuído de analisar seu lucro e descobrir possíveis restrições de gastos, para melhor resultado, observa-se que o fluxo de caixa deve ser aplicado por apenas uma pessoa, assim, possibilitando a aplicação dos investimentos e tomada de decisão através de relatório final. 
Conforme Araújo et al. (2015) sem a demonstração do fluxo de caixa torna-se inviável estimar a liquidez, fazer levantamento dos dados de entrada e saída, que permitiram a obtenção de informações necessárias para o planejamento e controle dos custos pelo gestor, assim como realizar projeções de recebimentos e pagamentos necessários para o crescimento e estabilidade com segurança das organizações.

No que tange o Balanço patrimonial, deve-se analisá-lo de forma vertical e horizontal, com o intuito de filtrar criteriosamente os tópicos e quadrantes dele. Conforme Cunha et al. (2017), a excelência das informações é de suma importância para os stakeholders e a qualidade das informações contidas nos relatórios gerenciais, é diferente dependendo da ótica de cada gestor, por conseguinte, o confronto entre várias informações é relevante para a elaboração do relatório final que será inserido no planejamento da empresa.

Por fim, as conciliações bancárias é a conferência entre os extratos bancários, as promissórias, boletos e pagamento, com a função de agrupar as contas a receber e a pagar, passando um pente fino no saldo de determinada conta bancária relacionada a empresa.

\subsection{Micro e pequena empresa: Fomento, Classificação e Determinantes de Sobrevivência}

Os órgãos de fomento agem como consultorias/assessorias para as Micro e Pequenas Empresas (MPE), ou seja, caso o empreendedor ou os seus colaboradores necessitem de qualquer tipo de apoio para elaboração do planejamento, organização, direção e controle, portanto, agindo como guia para direcionar o crescimento e desenvolvimento sustentável das empresas.

De acordo Sarfati (2013), apesar de não existir programas de fomento na esfera federal (com exceção do fomento vinculado a indústria Financiadora de Estudos e Projetos - FINEP) os municípios contam com iniciativas satisfatórias.

Lima e Oliveira (2016) realizaram uma investigação em Petrolina-PE relacionado aos órgãos de fomento que atuam no município, a motivação do estudo foi a importância dos órgãos de fomento em auxiliar essas empresas a expandir e se desenvolver, trazendo ideias inovadoras e agregando valor as mesmas. Alguns dos órgãos de fomento apontados nessa pesquisa foram: Expresso Empreendedor, SEBRAE, JUCEPE e AGEFEPE, conforme detalhado na Quadro 02.

Quadro 02: Órgãos de Fomento de Petrolina.

\begin{tabular}{|l|l|l|}
\hline Órgão de Fomento & Descrição & Fonte \\
\hline Expresso Empreendedor & $\begin{array}{l}\text { Orgão que atua em parceria e com } \\
\text { políticas públicas ligadas ao } \\
\text { SEBRAE. }\end{array}$ & Lima e Oliveira (2016) \\
\hline Casa do Empreendedor & $\begin{array}{l}\text { Atua prestando consultoria e } \\
\text { fornecendo ideias inovadoras } \\
\text { apara MPE iniciantes e existentes. }\end{array}$ & Lima e Oliveira (2016) \\
\hline $\begin{array}{l}\text { Serviço Brasileiro de Apoio às } \\
\text { SEBRAE e Pequenas Empresas - }\end{array}$ & $\begin{array}{l}\text { Sua atuação engloba consultoria, } \\
\text { cursos, palestras e publicações } \\
\text { com o objetivo de suprir a } \\
\text { necessidades do MPE }\end{array}$ & \\
\hline $\begin{array}{l}\text { Junta Comercial de Pernambuco - (2017) } \\
\text { JUCEPE }\end{array}$ & $\begin{array}{l}\text { Tem como “atribuição Legalizar, JUCEPE (2017) } \\
\text { arquivar e Executar os serviços de } \\
\text { registros públicos de empresas } \\
\text { mercantis e atividades afins no } \\
\text { Estado de Pernambuco.” }\end{array}$ & \\
\hline $\begin{array}{l}\text { Agência de Fomento de } \\
\text { Pernambuco - AGEFEPE }\end{array}$ & $\begin{array}{l}\text { Estrutura e viabiliza projetos } \\
\text { financeiros, através da concessão } \\
\text { de crédito, estimulando assim a } \\
\text { economia do estado }\end{array}$ & AGEFEPE (2017) \\
\hline
\end{tabular}

Fonte: SEBRAE (2017); JUCEPE (2017); AGEFEPE (2017). 
Sabe-se que as empresas podem ser classificadas mediante a sua renda bruta total anual ou pela quantidade de funcionários atuantes dentro da organização, dessa forma, dividindo e classificando-as em até cinco tipos, podendo ser estratificadas em microempreendedores individuais (MEI), microempresas, pequenas empresas, grandes empresas e Multinacionais. No entanto, as mais comuns estão entre microempresas a empresas de grande porte. Todavia, é preciso ressaltar que a divisão usada pelo SEBRAE não possui fins legais, valendo apenas as divisões previstas em Lei pela Agência Nacional de Vigilância Sanitária - ANVISA. Segundo Quadros 03 e 04.

Quadro 03: Classificação das Empresas de acordo com a ANVISA.

\begin{tabular}{|l|l|l|}
\hline Classificação & Faturamento Anual (em R\$) & Medida Provisória \\
\hline Microempresa & Igual ou inferior a 360.000,00. & $\mathrm{n}^{\text {o } 139 / 2011 .}$ \\
\hline Pequeno Porte & $\begin{array}{l}\text { Igual ou inferior a R\$ 3.600.000,00 e superior a R\$ } \\
360.000,00 .\end{array}$ & $\mathrm{n}^{\mathrm{o}} 139 / 2011$. \\
\hline Médio Porte & $\begin{array}{l}\text { Igual ou inferior a R\$ 6.000.000,00 e superior a R\$ } \\
3.600 .000,00 .\end{array}$ & $\mathrm{n}^{\text {o } 2.190-34 / 2001 .}$ \\
\hline Gr ande Porte & $\begin{array}{l}\text { Igual ou inferior a R\$ 50.000.000,00 e superior a R\$ } \\
6.000 .000,00 .\end{array}$ & $\mathrm{n}^{\text {o } 2.190-34 / 2001 .}$ \\
\hline
\end{tabular}

Fonte: ANVISA (2017).

Quadro 04: Classificação das Empresas de acordo com o SEBRAE.

\begin{tabular}{|l|l|l|}
\hline Porte & Serviço/Comércio & Indústria \\
\hline Microempresa & Até 9 pessoas ocupadas & Até 19 pessoas ocupadas \\
\hline Pequeno Porte & 10 a 49 pessoas ocupadas & 20 a 99 pessoas ocupadas \\
\hline Médio Porte & 50 a 99 pessoas ocupadas & 100 a 499 pessoas ocupadas \\
\hline Grande Porte & Acima de 100 pessoas ocupadas & Acima de 500 pessoas ocupadas \\
\hline
\end{tabular}

Fonte: SEBRAE (2014).

Abrir uma empresa requer bastante planejamento e uma certa experiência sobre o tipo de negócio que se pretende abrir, abaixo pode-se explorar alguns quadros, referente a fatores contribuintes a sobrevivência e mortalidade de 2.006 empresas criadas entre os anos de 2011 e 2012, de acordo com o SEBRAE (2016). Observa-se que a maior parte dos desempregados pertencem hoje ao grupo das empresas inativas conforme pode ser observado no Quadro 05, isto é, são pessoas com menor grau de experiência no ramo que foram motivados a abrir suas empresas com o propósito de suprir sua necessidade, aproveitando a demanda do produto/serviço exigida pelo cliente/fornecedor.

Quadro 05: Situação antes da abertura.

\begin{tabular}{|c|c|c|}
\hline Fatores Contribuintes & Empresas Ativas & Empresas Inativas \\
\hline Condição Anterior do Empresário & $\begin{array}{l}\text { MENOR proporção } \\
\text { desempregados }(21 \%)\end{array}$ & $\begin{array}{l}\text { MAIOR proporção } \\
\text { desempregados }(30 \%)\end{array}$ \\
\hline $\begin{array}{l}\text { Experiência anterior do } \\
\text { empresário }\end{array}$ & $\begin{array}{l}\text { MAIOR proporção de pessoas } \\
\text { com experiência anterior no } \\
\text { mesmo ramo }(71 \%)\end{array}$ & $\begin{array}{l}\text { MENOR proporção de pessoas } \\
\text { com experiência anterior no } \\
\text { mesmo ramo }(64 \%)\end{array}$ \\
\hline Motivação para abrir o negócio & $\begin{array}{llr}\text { MENOR proporção dos } & \text { que } \\
\text { abriram por exigência } & \text { de } \\
\text { cliente/fornecedor }(12 \%) & \end{array}$ & $\begin{array}{llr}\text { MAIOR proporção dos que } & \text { abriram por exigência } \\
\text { abria } \\
\text { cliente/fornecedor }(23 \%)\end{array}$ \\
\hline & $\begin{array}{l}\text { MAIOR proporção dos que } \\
\text { abriram porque identificaram } \\
\text { oportunidade ou porque } \\
\text { desejavam ter o próprio negócio } \\
(59 \%)\end{array}$ & $\begin{array}{l}\text { MENOR proporção dos que } \\
\text { abriram porque identificaram } \\
\text { oportunidade ou porque } \\
\text { desejavam ter o próprio negócio } \\
(49 \%)\end{array}$ \\
\hline
\end{tabular}

Fonte: SEBRAE (2016). 
Visualiza-se que empresas que planejaram estão, em sua maioria, ativas e, empresas que planejaram, inativas como pode ser observado no Quadro 06, demostrando que o planejamento é fundamental para a sustentabilidade de qualquer tipo de negócio, sendo necessário ter ou ir atrás do conhecimento associado ao tipo de negócio pretendido, por isso, pode-se negociar prazos, empréstimos com fornecedores e bancos para alimentar as funções básicas ao funcionamento da empresa.

Quadro 06: Planejamento.

\begin{tabular}{|l|l|l|}
\hline Fatores Contribuintes & Empresas Ativas & Empresas Inativas \\
\hline $\begin{array}{l}\text { Tempo médio de planejamento } \\
\text { antes de abrir a empresa }\end{array}$ & 11 meses & 8 meses \\
\hline Recursos & $\begin{array}{l}\text { MAIOR proporção que negociou } \\
\text { prazos com fornecedores ou } \\
\text { obteve empréstimo em bancos } \\
(39 \%)\end{array}$ & $\begin{array}{l}\text { MENOR proporção que negociou } \\
\text { prazos com fornecedores ou } \\
\text { obteve empréstimo em bancos } \\
(23 \%)\end{array}$ \\
\hline
\end{tabular}

Fonte: SEBRAE (2016).

Durante o funcionamento do negócio é importante observar e aperfeiçoar os produtos de acordo com a necessidade dos clientes, conforme pode ser visualizado no Quadro 07, trazendo diferenciação em relação aos produtos dos concorrentes, assim como investir na capacitação dos envolvidos no negócio para que a qualidade de serviço e dos produtos cresçam, sendo de responsabilidade do gestor estar sempre atualizado no contexto referente a novas tecnologias do seu setor de atuação, além de usufruir de ferramentas de gestão financeira para acompanhar com rigor o quadro de receitas e despesas.

Quadro 07: Gestão do negócio.

\begin{tabular}{|l|l|l|}
\hline Fatores Contribuintes & Empresas Ativas & Empresas Inativas \\
\hline $\begin{array}{l}\text { A empresa costumava com muita } \\
\text { frequência ... }\end{array}$ & $\begin{array}{l}\text { Aperfeiçoar sistematicamente seus } \\
\text { produtos e serviços as } \\
\text { necessidades dos clientes (95\%) }\end{array}$ & $\begin{array}{l}\text { Aperfeiçoar sistematicamente seus } \\
\text { produtos e serviços as } \\
\text { necessidades dos clientes }(84 \%)\end{array}$ \\
\cline { 2 - 3 } & $\begin{array}{l}\text { Investir na capacitação da mão de } \\
\text { obra e dos sócios (69\%) }\end{array}$ & $\begin{array}{l}\text { Investir na capacitação da mão de } \\
\text { obra e dos sócios (52\%) }\end{array}$ \\
\cline { 2 - 4 } & $\begin{array}{l}\text { Estar sempre atualizado com } \\
\text { respeito às novas tecnologias do } \\
\text { seu setor (89\%) }\end{array}$ & $\begin{array}{l}\text { Estar sempre atualizado com } \\
\text { respeito às novas tecnologias do } \\
\text { seu setor (78\%) }\end{array}$ \\
\hline $\begin{array}{l}\text { Realizar um acompanhamento } \\
\text { rigoroso da evolução das receitas e } \\
\text { das despesas ao longo do tempo } \\
(74 \%)\end{array}$ & $\begin{array}{l}\text { Realizar um acompanhamento } \\
\text { rigoroso da evolução das receitas e } \\
\text { das despesas ao longo do tempo } \\
(65 \%)\end{array}$ \\
\hline $\begin{array}{l}\text { Diferenciar produtos e serviços } \\
(31 \%)\end{array}$ & $\begin{array}{l}\text { Diferenciar produtos e serviços } \\
(24 \%)\end{array}$ \\
\hline
\end{tabular}

Fonte: SEBRAE (2016).

É estatisticamente significativo que pessoas com preparação se sobressaem em relação as que não tem, como pode ser constatado no Quadro 08. É preciso saber diferenciar administrador de empreendedor, pois em muitas empresas deparamos com empreendedores desqualificados, donos do negócio na zona de conforto que estarão à mercê da falência, já o administrador pode não ter a visão empreendedora, mas é preparado e treinado para administrar o negócio de qualquer empreendedor, da forma mais sinérgica possível, sendo que o perfil que parece ser mais apropriado para quem se aventura no mundo dos negócios é ser tanto administrador quanto empreendedor. 
Quadro 08: Capacitação em gestão.

\begin{tabular}{|c|c|c|}
\hline Fatores Contribuintes & Empresas Ativas & Empresas Inativas \\
\hline $\begin{array}{l}\text { Capacitação em gestão } \\
\text { empresarial }\end{array}$ & $\begin{array}{l}\text { MAIOR proporção que fez algum } \\
\text { curso para melhorar o } \\
\text { conhecimento sobre como } \\
\text { administrar um negócio, enquanto } \\
\text { tinha a empresa }(51 \%)\end{array}$ & $\begin{array}{l}\text { MAIOR proporção que fez algum } \\
\text { curso para melhorar o } \\
\text { conhecimento sobre como } \\
\text { administrar um negócio, enquanto } \\
\text { tinha a empresa }(34 \%)\end{array}$ \\
\hline
\end{tabular}

Fonte: SEBRAE (2016).

Em vista disso, pode-se entender que a empresa pode ruir em qualquer etapa do processo, desde o nascimento, logo, é preciso dispor, tanto de conhecimento quanto de ferramentas que auxiliem na manutenção do negócio, sendo uma das principais as de caráter financeiro, pois agem como termômetro para encontrar qualquer oscilação por qual a empresa deve estar preparada para contornar.

\section{Procedimentos Metodológicos}

A abordagem da presente pesquisa foi qualitativa, pois lida com fatos, procurando traduzir em números opiniões e informações para classificá-las e analisá-las. Assim, requerendo o uso de recursos e de técnicas estatísticas (KUARK; MANHÃES; MEDEIROS, 2010).

De acordo com os objetivos, os dados obtidos são de natureza descritiva que relata o maior número de elementos existentes na realidade examinada. Conforme Pradanov; Freitas (2013, p. 127), "expõe as características de uma determinada população ou fenômeno, demandando técnicas padronizadas de coleta de dados".

Foi utilizado a técnica de levantamento de dados tem como objetivo recolher informações de todos os integrantes por meio da interrogação direta das pessoas cujo o comportamento deseja conhecer e, em seguida, mediante a análise quantitativa, obter as conclusões correspondentes aos dados coletados (GIL, 2016).

A amostra investigada foram 48 restaurantes representada pelos seus respectivos gestores, gerentes do setor financeiro, localizados no município de Petrolina-PE, através da aplicação de questionário dividido em três seções, sendo a primeira o perfil da empresa, a segunda sobre as características do negócio e a terceira seção referente a perguntas da escala de frequência Likert.

As informações desta pesquisa foram obtidas por meio de questionário que, segundo Pradanov; Freitas (2013), constitui de uma série de perguntas que devem ser respondidas por escrito pelo participante. No questionário, foi utilizado 12 perguntas fechadas que apresentam alternativas fixas de múltipla escolha.

\section{Resultados e Discussão}

O resultado referente a função dos representantes dos empreendimentos e ao porte dos estabelecimentos em questão podem ser observados na Tabela 01. Destaca-se citar que desses estabelecimentos, cerca de 95,83\% deles possuem CNPJ e 4,17\% não, e que eles possuem uma média de 8 funcionários empregados por empreendimento.

Tabela 01: Função dos entrevistados e porte das empresas.

\begin{tabular}{c|c|c}
\hline Função & Quantidade & $\mathbf{\%}$ \\
\hline Caixa & 6 & $12,50 \%$ \\
\hline Gerente & 18 & $37,50 \%$ \\
\hline Proprietário & 21 & $43,75 \%$ \\
\hline Sócio & 3 & $6,25 \%$ \\
\hline Porte & Quantidade & $\mathbf{\%}$ \\
\hline MEI & 1 & $2,08 \%$
\end{tabular}




\begin{tabular}{c|c|c}
\hline $\mathrm{ME}$ & 35 & $72,92 \%$ \\
\hline $\mathrm{P}$ & 9 & $18,75 \%$ \\
\hline $\mathrm{M}$ & 2 & $4,17 \%$ \\
\hline $\mathrm{G}$ & 1 & $2,08 \%$ \\
\hline
\end{tabular}

Fonte: Pesquisa aplicada (2017).

Quando questionados se eles haviam estabelecido alguma parceria ou recebiam apoio de algum órgão de fomento da região, visualiza-se que aproximadamente $2 / 3$ das empresas não tem nenhum tipo de parceria com esses órgãos, como pode ser constatado na Tabela 02. Segundo a pesquisa realizada por Lima e Oliveira (2016) cerca de 13\% das empresas do setor alimentício da região de Petrolina são clientes atendidos por órgãos de fomento, entrando em concordância com a pesquisa realizada, onde foi encontrado um percentual de $29,17 \%$ em parceria com SEBRAE, evidencia-se que especificadamente referente a restaurantes, esse número representa mais que o dobro do setor em geral da região.

Tabela 02: Parceria entre empresas e órgãos de fomento.

\begin{tabular}{l|l}
\hline Não possuem parceria & $68,75 \%$ \\
\hline SEBRAE & $29,17 \%$ \\
\hline JUCEPE & $4,17 \%$ \\
\hline AGE & $0,00 \%$ \\
\hline Casa do Empreendedor & $0,00 \%$ \\
\hline Expresso Empreendedor & $0,00 \%$ \\
\hline Outros & $0,00 \%$ \\
\hline
\end{tabular}

Fonte: Pesquisa aplicada (2017).

Com relação aos problemas enfrentados para realização do planejamento e controle, verificou-se que a maioria dos participantes não passam por nenhum tipo de problema, como está apresentado na Tabela 03.

O que corrobora, relativamente, com as informações do SEBRAE (2016), em que cerca de 31\% das empresas ativas não investem na capacitação de mão de obra e dos sócios. Por sua vez, nos achados da presente pesquisa, a minoria dos gestores dos restaurantes acredita que a falta de capacitação para aplicação de ferramentas de gestão representa um problema.

Contudo, ainda de acordo com o SEBRAE (2016), cerca de 39\% das empresas ativas negociam prazos com fornecedores ou obtém empréstimos em bancos para dar continuidade a suas atividades e investimentos, enquanto uma parte dos restaurantes carecem de recursos para implementação de ferramentas financeiras.

Nesse sentido, de acordo com Lima e Oliveira (2016) a Secretaria do Orçamento e Gestão do município de Petrolina - MOG através da AGE e em parceria com SEBRAE, permite empréstimos a MPE com taxa de juros de $1 \%$ a.m., mostrando que há possibilidade de parceria entre os restaurantes e órgãos de fomento para capacitação e fornecimento de crédito colaborando, assim, para o pleno crescimento dos mesmos, além de suprir a necessidade de planejamento estratégico e/ou financeiro carentes nos restaurantes, já a maioria dos restaurantes pesquisados afirmar que não passam por nenhum tipo de problema.

Tabela 03: Problemas enfrentados no planejamento e controle.

\begin{tabular}{l|c}
\hline Falta de Planejamento estratégico e/ou financeiro & $18,75 \%$ \\
\hline Falta de capacitação para aplicação de ferramentas de gestão & $16,67 \%$ \\
\hline Falta de recursos financeiros para implementação das ferramentas & $20,83 \%$ \\
\hline Não passa por nenhum tipo de problema & $56,25 \%$ \\
\hline Outros & $2,08 \%$ \\
\hline
\end{tabular}

Fonte: Pesquisa aplicada (2017).

As ferramentas mais utilizadas pelos restaurantes em seus controles financeiros estão expostas na Tabela 
04, onde, como esperado, o fluxo de caixa é a ferramenta mais utilizada, seguida do controle de custos.

Nos achados de Araújo et al. (2015) a minoria dos gestores entrevistados afirmara que não há necessidade do uso de ferramentas financeiras dada ao respectivo controle existente no negócio e uma porcentagem dos gestores não sabiam da existência dessas ferramentas.

Tabela 04: Ferramentas financeiras utilizadas pelos gestores de restaurantes do município de Petrolina.

\begin{tabular}{l|c}
\hline Controle de custos & $66,67 \%$ \\
\hline Auditória interna & $22,92 \%$ \\
\hline Fluxo de caixa & $77,08 \%$ \\
\hline Balanço patrimonial & $27,08 \%$ \\
\hline Conciliações bancárias & $31,25 \%$ \\
\hline
\end{tabular}

Fonte: Pesquisa aplicada (2017).

Dentre as principais alternativas de dificuldades elencadas pelo entrevistador, destacam-se os juros altos e o baixo volume de vendas, como pode ser observado na Tabela 05.

Contudo, de acordo com os SEBRAE (2014) os impostos representam apenas cerca $6 \%$ do total de causa mortis das empresas, já 19\% dessas mortis são representadas por falta de capital/lucros, seguida da mudança para outras atividade $14 \%$, falta de clientes e problemas particulares $9 \%$ cada e perda do cliente único e problemas de planejamento/administração $8 \%$ cada que culminará em baixo volume de vendas e falta de capital de giro.

Por sua vez, de acordo com os gestores entrevistados, a principal falta é a pequena quantidade de vendas em relação as despesas. Salienta-se que, de acordo com SEBRAE (2016) a taxa de mortalidade de empresas de 2 anos constituídas em 2012 em Petrolina era de 27\%, dos quais estão inclusos os restaurantes, resultado aceitável, tendo em vista que existe uma grande diversidade de empresas.

Tabela 05: Problemas enfrentados pelos restaurantes do município de Petrolina.

\begin{tabular}{l|c}
\hline Limite de crédito baixo no banco & $27,08 \%$ \\
\hline Dificuldade de acesso aos bancos & $12,50 \%$ \\
\hline Juros altos & $60,42 \%$ \\
\hline Baixo volume de vendas & $33,33 \%$ \\
\hline Descompasso quanto ao recebimento de suas vendas e o respectivo pagamento aos seus fornecedores & $8,33 \%$ \\
\hline Outros & $16,67 \%$ \\
\hline
\end{tabular}

Fonte: Pesquisa aplicada (2017).

Quando examinados se já ocorreram situações em que a conta bancária esteve negativa por determinado período por não ter sido percebida anteriormente, pode-se visualizar na Figura 01 que grande parte deles afirmaram que nunca esteve negativa, informação que pode ser acompanhada e projetada previamente através do acompanhamento dos índices financeiros. Seguindo a premissa abordada na pesquisa de Araújo et al. (2015) através do DFC, seja ele direto ou indireto, é possível visualizar empréstimos, financiamentos e investimentos vigentes na empresa durante determinado período, então torna-se descompasso por parte do gestor deixar passar tal informação por não ter sido acompanhada regularmente, sendo presentes em aproximadamente 2 em cada 10 empresas. 
Figura 01: Situação negativa na conta bancária.

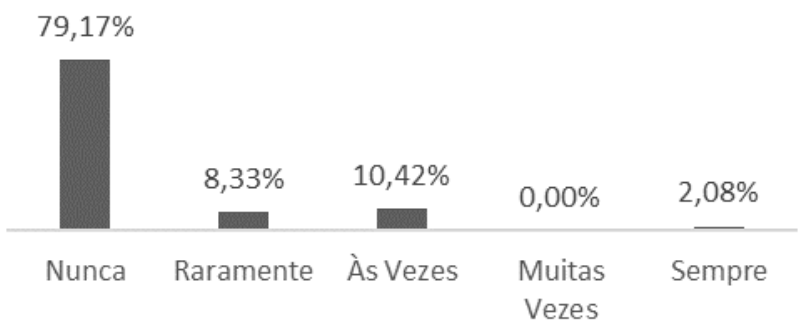

Fonte: Pesquisa aplicada (2017).

Perguntou-se, se quando é preciso fazer compras para casa, existem situações em que é utilizado dinheiro da empresa para tal fim, as respostas estão apresentadas na Figura 02, a maioria dissera que nunca, todavia, observou-se que alguns gestores que utilizam dinheiro da empresa, podendo comprometer a atividade operacional do negócio.

Nesse sentido, Bertini (2017) pontua que o pró-labore é a remuneração dos proprietários e sócios do negócio, deve ser definido de forma a não impactar e misturar o que é físico e jurídico, portanto, deve ser definido um montante de forma que não impacte negativamente a empresa, porém contraditória a essa definição, mais da metade dos responsáveis pelos restaurantes costuma fazer retiradas periódicas.

Figura 02: Pessoa física e jurídica.

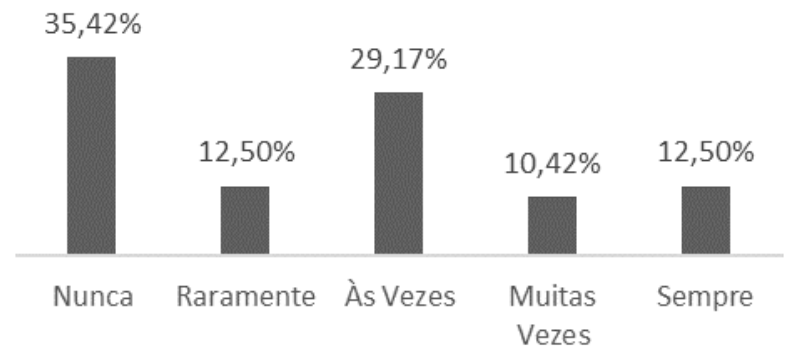

Fonte: Pesquisa aplicada (2017).

Quando indagados se a empresa já teve alguma despesa não programada que tenha prejudicado seus resultados no final do período, evidencia-se na Figura 03 que a maioria dos empreendedores já teve alguma despesa não programada, ou seja, não possui um rígido controle de custo e folga no seu disponível, uma vez que mais da metade alega que já passou por situações que afetaram seu resultado operacional.

Apesar disso, entede-se que os empreendedores do setor de restaurantes, poderiam estar realizando um controle mais detalhado dos seus custos, como pôde-se observar o modelo de mensuração avaliado por Nogueira (2016) em sua investigação, a contabilidade de custos, é bastante flexível, adaptando-se em outros tipos de serviços e produtos como forma de redução de desperdício, controle e projeção de cálculos semanais, mensais e anuais, conhecendo suas principais despesas e insumos, assim como no caso de restaurantes, pratos com maior saída, seja no local ou delivery.

Figura 03: Despesas não programadas.

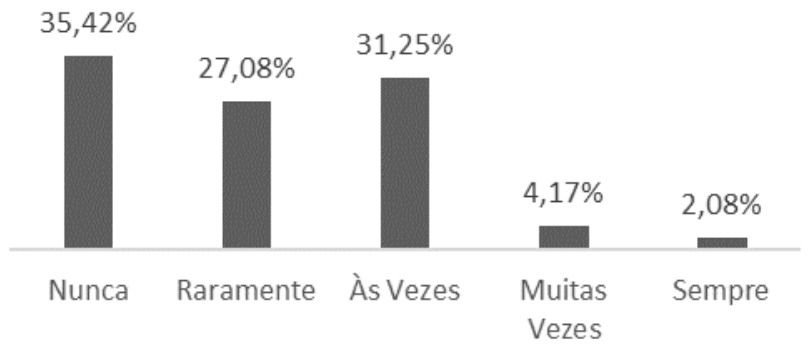

Fonte: Pesquisa aplicada (2017). 
Por fim, buscou-se identificar se a empresa consegue manter um nível adequado de capital de giro para sua gestão. Para Borges et al. (2017) as flutuações do mercado impulsionam a demanda positivamente e negativamente, com isso as decisões financeiras tornam-se mais restritas, tanto para as empresas como para o consumidor que passa a comprar menos, girando cada vez menos o estoque, prejudicando o exercício mensal da empresa, assim como qualquer negócio os restaurantes precisam atingir uma cota mínima de vendas para então começar a obter seu lucro e o montante necessário para iniciar o caixa no dia seguinte.

Conforme os resultados encontrados, que podem ser observados na Figura 04, a grande maioria das empresas conseguem, no entanto, a falha no seu capital de giro pode estar relacionado aos índices negativos decorrentes aos problemas abordados anteriormente, é preocupante a situação dos demais restaurantes, pois o capital de giro é importante para manter a atividade operacional do estabelecimento.

Figura 04: Nível de capital de giro.

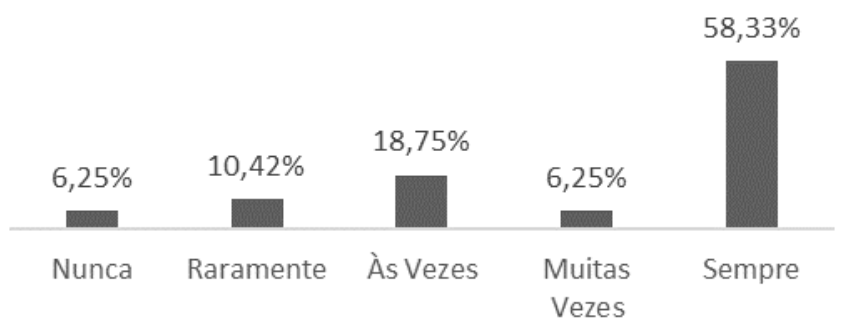

Fonte: Pesquisa aplicada (2017).

Em suma, percebe-se que há possíveis relações entre as variáveis, pois se um empreendedor não tiver determinado sua remuneração em forma de pró-labore, ou seja, tenha clareza sobre o capital que é da empresa e o capital que é do proprietário, pode acabar por interferir diretamente em fatores como falta de capital de giro que, por consequência, poderá negativar sua conta bancária mediante empréstimos solicitados para manter esse giro, como efeito a empresa não terá reserva para despesas não programadas.

Os gestores e proprietários parecem não estar tendo uma visão alinhada com a realidade, pois, apesar de ser um ramo específico, o de restaurantes, a diferença em algumas informações é significativa. Enquanto a maioria relata ter problemas com juros altos, o SEBRAE (2014) apresenta uma visão mais abrangente mostrando que esse problema é irrisório, pois é uma mínima proporção do total das causas mortis.

Como foi possível constatar, a maioria desses restaurantes não tem parceria com órgãos de fomento que poderia prestar suporte, auxílio e fornecer informações relevantes para alavancar essas empresas, apesar de todas usarem uma ou mais ferramentas, contudo, acredita-se que quanto mais domínio de qual ferramenta financeira o gestor deverá usar para controle e planejamento, melhor poderá ser a visão financeira do negócio mediante as adversidades.

\section{Considerações Finais}

Sabe-se que planejamento financeiro é importante para a criação bem sucedida de uma empresa, oriundas do projeto de viabilidade econômica, ou seja, antes do negócio funcionar, o gestor pode considerar ter contato e conhecimento das ferramentas financeiras, projetando suas despesas e receitas, como forma de analisar a viabilidade de seu empreendimento e, com isso, podendo se sobressair frente aos seus concorrentes, mantendo-se competitivo, por intermédio do controle, investimento e aplicação de seus recursos, para que então se tenha o resultado esperado.

Em referência a questão problema que norteou essa pesquisa, que foi: Os gerentes de restaurantes estão cientes da existência e aplicação das ferramentas financeiras, ou seja, quais ferramentas financeiras são utilizadas pelos restaurantes da cidade de Petrolina? Pode-se inferir que: aproximadamente 3 em cada 4 gerentes estão cientes da existência das ferramentas financeiras e utilizam ao menos uma, sendo a de maior destaque o fluxo de caixa. Observou-se também que 16,7\% deles passam por dificuldade de capacitação para aplicação dessas ferramentas, havendo também uma falta de domínio, versatilidade e aplicação de várias ferramentas ao mesmo tempo que acabar por impactar negativamente a empresa, findando o objetivo de identificar às ferramentas financeiras utilizadas no auxílio à gestão financeira por gerentes de restaurantes da cidade de Petrolina. 
Sabe-se que informações podem ser extraídas por intermédio dessas ferramentas, de acordo com a necessidade do gestor e com intuído de manter em plenitude as funcionalidades do negócio, aproveitando as oportunidades e driblando com eficácia as ameaças.

Observou-se que muitos gestores não possuem parcerias estratégicas de capacitação através dos órgãos de fomento, uma vez que além de fornecer crédito com maior facilidade, oferecem cursos de capacitação que irá ajudar o gestor ou funcionário ampliar sua habilidade no uso de ferramentas diversas, pois há muita falta de planejamento estratégico e/ou financeiro que por consequência impedem de projetar seus custos e investilos de forma que atraia mais clientes.

Foi perceptível que muitos gestores não fazem uso de movimentações bancárias com objetivo de usufruir dos juros provenientes do investimento de seu lucro, tornam-se por quase $2 / 3$ dos casos a fazer retiradas da empresa, para gastos fora da atividade operacional da empresa, que por muitas vezes tarda, mas cobra através de despesas não programas que por muitas veze poderiam ter sido evitadas e que no pior das hipóteses carecerão de falta de capital de giro.

Através da saturação de restaurantes muito próximos, principalmente no raio do centro da cidade, cabe aos gestores procurar um meio de se diferenciar dos concorrentes para garantir sua cartela de clientes, no entanto isso só será possível através do uso de ferramentas financeiras e parcerias estratégicas, que com o tempo darão retorno através da visão apurada em prever situações adversas do mercado e saber contorna-las. Observou-se que quanto maior o porte do restaurante maior era a organização e o pleno uso de diversas ferramentas pesquisadas, assim como houve pequenos que estão crescendo de forma estruturada através do uso delas.

Houve limitações no estudo referente a resistência dos entrevistados e por vezes não ser o proprietário, gerente ou sócio que tenha respondido o questionário, deveria ter sido perguntado o nível de escolaridade do gestor afim de fazer um comparativo com os resultados, o número de questões poderia ser melhor trabalhado, pois houve informações que tiveram que ser excluídas devido a limitações acadêmicas, por se tratar de uma pesquisa ainda inexistente no município de Petrolina tornou-se bastante trabalhosa.

Recomenda-se novas investigações ainda na área financeira, em que os dados qualitativos sejam cruzados, por exemplo, poderia ser utilizado o teste estatístico não paramétrico qui-quadrado, que permitiria identificar se existe alguma associação entre as variáveis. Ou seja, o bom desempenho financeiro independe da utilização de ferramentas financeiras? Quais ferramentas financeiras estão associadas ao bom desempenho? Essa resposta não foi possível obter nesta pesquisa pela não aplicação do teste.

\section{REFERÊNCIAS}

ARAÚJO, A; TEIXEIRA, E. M.; LICÓRIO, C. (2015). A importância da gestão no planejamento do fluxo de caixa para o controle financeiro de micros e pequenas empresas. REDECA: Revista eletrônica do departamento de ciências contábeis \& departamento de atuária e métodos quantitativos da FEA, 2, (2), 7388, Jul./dez. Recuperado em 27 de nov. de 2017, de https://revistas.pucsp.br/index.php/redeca/article/view/28566.

AGEFEPE. Institucional - AGEFEPE. (2017) Recife: AGEFEPE. Recuperado em 20 ago. 2017 de http://www.lai.pe.gov.br/web/agefepe/institucional.

ANVISA. Porte de Empresa. (2017) Brasília: ANVISA. Recuperado em 20 ago. 2017 de http://portal.anvisa.gov.br/porte-de-empresa?inheritRedirect=true.

BERTINI, D. H. A vedação de cláusulas leoninas e o pró-labore. (2017) Vitória. Recuperado em 27 nov. 2017, de https://dhbertini.jusbrasil.com.br/artigos/425834447/a-vedacao-de-clausulas-leoninas-e-o-pro-labore.

BORGES, G. R.; DIEL, F. J.; FERNANDES, F. C. (2015). A contribuição da auditoria interna de riscos para o planejamento de organizações na área de saúde. Revista de gestão em sistemas de saúde, São Paulo, 4, (2), 9-27. Recuperado em 23 ago. 2017, de: http://www.spell.org.br/documentos/ver/39500/a-contribuicao-daauditoria-interna-de-riscos-p---.

BORGES JUNIOR, D. M.; SARVAS, L. A. D.; OLIVEIRA, J. R.; RIBEIRO, K. C. S. (2017). Gestão do Capital de Giro e Desempenho em Tempos de Crise: Evidências de Empresas no Brasil, América Latina e 
Estados Unidos. Reunir: Revista de administração, contabilidade e sustentabilidade, Campina Grande, 7, (2), 1-12. Recuperado em 23 ago. 2017 de http://www.spell.org.br/documentos/ver/47053/gestao-do-capital-degiro-e-desempenho-em-tempo---.

BRAGA, R. (2015) Fundamentos e técnicas de administração financeira. 1.ed. São Paulo: Atlas.

CERVO, A. L.; BERVIAN, P. A.; SILVA, R. (2007) Metodologia científica. 6.ed. São Paulo: Pearson Prentice Hall.

CUNHA, P. R.; FERNANDES, L. B.; MAGRO, C. B. D. (2017) Influência do Refazimento das Demonstrações Contábeis no Gerenciamento de Resultados das Empresas Listadas na BM\&F Bovespa. RACE: Revista de administração, contabilidade e economia, Joaçoba, 16, (1), 95-120. Recuperado em 22 ago. 2017, de http:/www.spell.org.br/documentos/ver/44805/influencia-do-refazimento-das-demonstracoescontabeis-no-gerenciamento-de-resultados-das-empresas-listadas-na-bm-fbovespa.

GIL, A. C. (2016) Como elaborar projetos de pesquisa. 5. ed. São Paulo: Atlas.

JUCEPE. (2017). JUCEPE - Junta comercial do estado de Pernambuco. Recuperado em 20 ago. 2017, de http://www.pe.gov.br/orgaos/jucepe-junta-comercial-do-estado-de-pernambuco/.

JUNIOR, C. C. (2017). Contabilidade de custos aplicada no preço de venda dos produtos. Revista gestão em foco. Amparo, 9, (1), 51-59. Amparo-SP. Recuperado em 23 de nov. 2017, de http://portal.unisepe.com.br/unifia/wp-

content/uploads/sites/10001/2018/06/009_contabilidade_custos_aplicada_pre\%C3\%A7o_venda_produtos.pdf.

KUARK, F.S; MANHÃES, F.C; MEDEIROS, C. H. (2010) Metodologia da pesquisa: um guia prático. Itabuna: Via Litterarum.

LAKATOS, E. M.; MARCONI, A. M. (2003) Fundamentos de metodologia científica. 5.ed. São Paulo: Atlas.

LEONE, G. S. G. (2014) Custos: Planejamento, implantação e controle. 3.ed. São Paulo: Atlas.

LIMA, A. M. C. de O.; OLIVEIRA, E. M. J. (2017). Panorama do fomento ao empreendedorismo das MPE'S no município de Petrolina-PE. Revista Expansão Acadêmica. Juazeiro, 4, (1), 36-52, jan./jun. Recuperado em 20 ago. 2017 de http://www.expansaoacademica.com/wp-content/uploads/2017/07/Edição-4-Completa.pdf.

LINS, L. S. (2014). Auditoria: uma abordagem prática com ênfase na auditoria externa (2014) 3.ed. São Paulo: Atlas.

NOGUEIRA, D. N. G.; CASTILHO, V. (2016). Resíduos de serviços de saúde: mapeamento de processo e gestão de custos como estratégias para sustentabilidade em um centro cirúrgico. Revista de gestão, São Paulo, 23, (4), 362-374. Recuperado em 23 de nov. 2017 de http://www.revistas.usp.br/rege/article/view/129044/125697.

PRADANOV, C. C; FREITAS, E. C. (2013) Metodologia do trabalho científico: Métodos e Técnicas da pesquisa e Trabalho Acadêmico. Novo Hamburgo: Universidade Feevale.

RIBEIRO, D. B.; ESTENDER, A. C. O. (2017) Fluxo de Caixa na Organização Borgatto Compercio e Empreendimentos Ltda. Revista Administração em Diálogo, São Paulo, 19, (2), Mai/Jun/Jul/Ago, $42-61$. Recuperado em 25 de nov. 2017, de https://revistas.pucsp.br/rad/article/view/29453.

SARFATI, G. (2013) Estágio de desenvolvimento econômico e políticas de empreendedorismo de micro e pequenas empresas (MPEs): os casos do Brasil, Canadá, Chile, Irlanda e da Itália. Revista de Administração Pública, Rio de Janeiro, 47, (1), 25-48. Recuperado em 23 de nov. 2017 de http://www.spell.org.br/documentos/ver/9463/estagios-de-desenvolvimento-economico-e-politicas-publicasde-empreendedorismo-e-de-micro--pequenas-e-medias-empresas--mpmes--em-perspectiva-comparada--oscasos-do-brasil--do-canada--do-chile--da-irlanda-e-da-italia.

SEBRAE. (2017) Gestão financeira. Brasília: SEBRAE. Recuperado em 16 maio, 2017 de http://www.sebraepr.com.br/PortalSebrae/artigos/Gest\%C3\%A3o-Financeira. 
(2014). Empreendedorismo_ no Brasil: relatório executivo de 2001-2013. Curitiba: IBQP. Recuperado em 20 ago. 2017 de http://www.ibqp.org.br/.

(2016). Sobrevivência das empresas no brasil. Brasília: SEBRAE. Disponível em: http://www.sebrae.com.br/Sebrae/Portal\%20Sebrae/Anexos/sobrevivencia-das-empresas-no-brasil-relatorio2016.pdf. Acesso em: 20 ago. 2017.

- (2017) O que fazemos. Brasília: SEBRAE. Recuperado em 20 ago. 2017, de http://www.sebrae.com.br/sites/PortalSebrae/canais_adicionais/o_que_fazemos.

- (2014) Causa mortis: o sucesso e o fracasso das empresas nosprimeiro 5 anos de vida. São Paulo: SEBRAE. $\quad$ Recuperado em $27 \quad 27$ nov. https://m.sebrae.com.br/Sebrae/Portal\%20Sebrae/UFs/SP/Anexos/causa_mortis_2014.pdf.

SCHNEIDER, Ido José; GRANDO, Neiva Ignês. Matemática financeira: relações entre situações reais e educação para o consumo. REVEMAT: Revista eletrônica de educação matemática, Florianópolis, 6, (2), 8195, 2011. Recuperado em 27 de nov. 2017, de: https://periodicos.ufsc.br/index.php/revemat/article/viewFile/1981-1322.2011v6n2p81/21793. 